\title{
Revisiting the Metaphysical Verses of Wei and Jin Dynasties: The Combination of Philosophical Discourse and Literary Discourse
}

\author{
Qun Yang \\ Jiangxi Science and Technology Normal University, Nanchang, Jiangxi, 330000
}

\author{
Keywords: Metaphysical Poetry, Literary Discourse, Imagery
}

\begin{abstract}
Metaphysical Poetry in Wei and Jin Dynasties is a specific product of the intersection of Metaphysics and Literature in the context of a specific era. For the literary value of Metaphysical Poems in Wei and Jin Dynasties, there are many disputes between ancient and modern scholars. Against this background, it is necessary for us to review the literary value of the metaphysical poems in Wei and Jin Dynasties from the literary discourse studies in the modern era. From this point of view, the Wei and Jin metaphysical poems although their own artistic elements are not rich enough, but the Wei and Jin poet's metaphysical poem writing process after all is a pioneering and far-reaching discourse fusion practice.
\end{abstract}

\section{Introduction}

Metaphysical poetry prototype originated in the beginning of the rise of metaphysics, but the mysterious language as a style of poetry in the late Western Jin Dynasty began to formally formed, to the Eastern Jin Dynasty became a popular style of creation. The literati at this time wrote a large number of metaphysics to elucidate the metaphysics, discusses the works of Lao Zhuang's poetry, poetry Xuan Yi, collectively referred to as the hymn verse. Intuitively, Xuan Yan Poetry is the most direct intersection of Metaphysics and Wei and Jin Dynasties literature, is to explore the metaphysics and the Wei and Jin Dynasties literature can not be left untouched topic. This essay attempts to clarify the nature of the discourse of the hymn verse and to explore the profound influence of hylogent verse on the literary discourse of the Wei and Jin Dynasties from the perspective of the study of contemporary literary discourse.

\section{The Profound Evaluation of Poetry Literature}

Needless to say, from ancient times, the scholars mainly lay emphasis on the negative evaluation of the literary value of the hymn verse. Most of these works copied the metaphysical words and expressions of the Three Mysteries and the Buddhist Scriptures. Their language is empty and mysterious. It deviates from the basic attributes of literature - vividness and lyricism, and thus soon suffers from the widespread criticism of Southern literary critics. For example, Zhong Rong's "Poems and Articles" put forward: "When Yongjia, you are a little old, a little faint. When the articles, go hand in hand, frivolous taste. Jiang table, microwave Shang Chuan, Sun Chuo, $\mathrm{Xu}$ inquiry, Huan, Zhu poem, are similar to the classic code of ethics. "Liu Xuan" Wen Xin Diao Long • Ming Poems "also evaluated as:" Jiang Zuo chapter system, addicted to Xuan Feng, laugh at the mission of Zhi, Chongsheng forget Machine talk, Yuan Sun has been under, although each carving mining, and $\mathrm{Ci} \mathrm{Ci,} \mathrm{Mo} \mathrm{and} \mathrm{Zhengxiong,} \mathrm{so} \mathrm{Jing} \mathrm{pure} \mathrm{"cents} \mathrm{articles",} \mathrm{upright} \mathrm{and} \mathrm{Jun} \mathrm{carry} \mathrm{on.} \mathrm{,}$ And landscape Fang $\mathrm{Zi}$; Li mining hundred words even, the odd price of a fight, the situation will be extremely emotional writing, rhetorical inevitability and chasing new, competing in the near future also.

The poem, which should have the spirituality of art, has been written as a "canonical" theory of "morality." This sentence from Zhong Rong tells us exactly what is wrong with common mistakes later in life. Liu Xun pointed out even more: when the mysterious poetic poetry prevailed, only Guo Pu's "fairy poem" and a few nonphysical works can stand out from the crowd, while the rise of landscape poetry in the late Jin and early Song Dynasties was represented by the literary 
magnanimity The wind's retreat for the logo. In fact, the hymn-verse works that have been handed down so far are just a few of the products made by the poets at the time, and the times of the life of Liu Xie and Zhong Rong are closer to the time when the mysterious verse was popular, which can generally see the whole picture of hymn verse. Considering these factors, Liu Xie and others on the evaluation of Xuan Yan Poems should be based on a sufficient basis. In this way, we present a dilemma for researchers of today, especially Wei and Jin literature: whether or not hyacinth poetry has no literary value and how it should be located in the history of literature?

What is interesting is that there are always two opposite paths to the study of hyun verse by contemporary scholars. One is inherited Liu Yong and Zhong Rong, who concluded that the role of metaphysical poetry for literature is negative, and even "no literature in Eastern Jin Dynasty," said. Secondly, it tries to find the positive function of Yuanyan Poem for the development of literature, and even enlarge the outer edge of Yuanyan Poetry. Some of the literary works, such as Ruan Ji, Ji Kang and Tao Yuanming, The fairy poetry into the category of mysterious words.

The author believes that the above two research paths are not enough objective place. As a mainstream style of Eastern Jin literature, the profound poem poetry certainly can not write off the positive influence on the development of literature in the Wei and Jin Dynasties and even the entire Chinese literature. That is to say, the argument that the art value of Xuan Yan Poem should be denied is aimed at the "Xuan Yan" theory of Xuan Yan Poetry; while the theorists who try to affirm Xuan Yan Poems often skip the "Xuan Yan" part of Xuan Yan Poem directly And even discussed is not a hymn verse. The same is the "mysterious words poem" research, the object of study has actually been different, it is no wonder each other's conclusions each speaks, incomprehensible.

So, scholars in the study of how to look straight into the "unspoken" mysterious words "mysterious words"? Is it still the "true" metaphysical verse that left the hymn verse of "The Metaphysical Word"? Is not the hymn verse filled with philosophical discourse useful for the development of literature? There are both stylistic ambiguity and value judgments in this episode.

\section{The Essence of Discourse Poetry}

In essence, to avoid the embarrassment in the study of the hymn verse and to restore the discourse essence of the hymn verse, it is necessary for us to review the literary value of the metaphysical verse in the Wei and Jin Dynasties from the study of literary discourse in the contemporary ascendant. With the deepening of literary discourse research, people have found that there are obvious differences between literary discourse and daily discourse and scientific discourse. The basic characteristics possessed by literary discourse are the basic elements of literature. Of course, in the actual practice of discourse, various discourses can communicate with each other. From this point of view, the discourse essence of the hymn discourse is actually the product of the integration of the discourse of discourse and the discourse of literature.

Metaphysical discourse is the metaphysical meaning of interpretation, belonging to the philosophical discourse, had no direct connection with literary creation. However, scholars from the Jin dynasty will create poetry as a form of body mystery, so that the profound discourse will be directly integrated into literary works. In fact, not only poetry, in the creation of fu, at that time, taxis also had such attempts, such as shameful "meaning" and so on. This is what the preceding quote Liu Li said, "the poem will be under the purport of $\mathrm{Zhu} \mathrm{Xi,} \mathrm{Fu} \mathrm{Yi} \mathrm{Park} \mathrm{is} \mathrm{the} \mathrm{meaning} \mathrm{of}$ justice." However, the artistic value of these works is extremely limited and received many negative comments after the Southern Dynasty. They were basically ignored in the literary anthologies of later generations and have not been preserved.

Generally speaking, an ideology exerting an influence on the development of literature will always form the corresponding cultural thoughts first, and then affect the literary aesthetic tendencies and values, which will eventually be implemented through the selection of topics and concrete expressions of literary creation Skills and other specific aspects. However, in the Wei and Jin dynasties, as a metaphysical theory of the mainstream ideology at that time, there appeared a trend of discourse fusion with literary creation. Only by fully recognizing the nature of this discourse of the hymn verse, it is possible to objectively analyze the artistic techniques and literary 
values of the hymn verse.

\section{The Fusion Morphology Analysis of Metaphysical Discourse and Literature Discourse}

As mentioned above, the nature of the discourse of Xuan Yan Poetry is the fusion of Metaphysical discourse and literary discourse. It is analyzed concretely from the angle of literature study. The fusion consists of two aspects: the first level is metaphysics and related vocabulary into the literary text; The second level is the change of discourse style brought by metaphysical vocabulary after entering literary discourse.

Metaphysical vocabulary into literary texts, as the main language elements of Hyun Poem, this is the most intuitive impression Yuanshitai poetry to people, mysterious verse is precisely because of these "mysterious words" named. The "mystery" here can be subdivided into two situations. The first is that the metaphysical vocabulary of metaphysics goes directly into literary texts and becomes a part of the compositional elements of literary works. This kind of vocabulary is far from the requirement of literary nature, and can only be applied in specific occasions of mysterious poetry, so it has little effect on future generations. Since the Southern Dynasties metaphysics as a mainstream academic exit the stage of history, the true "Metaphysical" in the hymn verse also gradually neglected, not elaborated here.

The second is that some of the images used to elucidate metaphysics enter the literary texts in the face of common vocabulary. These images are mostly natural images of discourse, but after metaphysics "infiltration", obviously has the spirit of the metaphysical pursuit. They can be broadly divided into categories such as gardens, stars, valleys, dew, clouds, fish and trees, grass trees, etc. There are dozens to hundreds of commonly used words in each category. These vocabulary itself is divided into two kinds: one is to give something kind of rational meaning, such as secluded house, Lingshan, Supra, Shenfeng, Mizuno and so on. The other is to reveal the actual existence of natural images such as breeze, birds, songbirds, Gao Lin, Xiuzhu, Hanquan, clouds and so on. Some of these words have appeared in previous literary works, and some were not widely adopted until after the rise of the hymn verse. Some of them are still alive with vitality even after they have escaped the metaphysical poem. Since then, they have been chanted repeatedly by the people of Xuan Wen into the core vocabulary of ancient Chinese literature. Therefore, even in the Tang Dynasty where the poetic literature was magnificent, we could still see these words that were used to describe metaphysical images. Some of them even became the common images in Chinese classical literature and aesthetics.

This is the second level of integration of metaphysical discourse and literary discourse, and also a level rarely touched before in the academic world. Different types of vocabulary often mean different ways of expression. "Metaphysics" enters poetry and becomes "hymn verse". This process is not only a substitution and replacement of vocabulary, but also a change of discourse style. Mr. Zhu Ziqing noticed this shift with great sensitivity. He pointed out in his article "Preface to the Poems in Daily Life - A Preface to Xiao Yuanqing's Criticism of Tao Yuanming." Although Tao Shih obviously accepted the influence of Yuanyan Poems, Old, "' Zhuang, "and ended up using the same language as" a language that is relatively close to speaking. "Because only 'a language that is relatively close to speaking' can be compared to the best of the best, the words of both husband and wife can not So straightforward. "

Mr Zhu Ziqing's remark discovers the discourse characteristic of the hymn verse from the perspectives neglected by other scholars, that is, "a language that is relatively close to speaking." This thesis contradicts the established view that people are profound and mysterious, but best reveals the "non-literary" features of the metaphorical discourse. That is to say, what Mr. Zhu Ziqing refers to here as a "language of speech" does not actually refer to a specific term item, but rather to a discourse method. Although the vocabulary of Metaphysics and Buddhist Scriptures is different from the everyday language used in today's understanding, they are not unique in the context of the time. More importantly, this practice of moving the righteousness and related images into poetry determines that the hymnist people must To use more "close to speech" discourse to express, over-written form of the couple in this case is difficult to play an effect. In this way, 
attempts to enter philosophical discourse of philosophical discourse may seem unsuccessful, but new attempts to bring about deep discourse will affect the core of literary development with no trace.

\section{Review the Value of Xuan Yan Poem Discourse Practice from the Evolution of Philosophical Poems}

The previous analysis of the essence of the metaphysical poem writing as a discourse practice, from which we can see that the metaphysical poem is not equivalent to a simple superposition of the metaphor and literary language, of course, the value of the metaphorical poem can not be judged too arbitrary.

Literary critics such as Liu Xie and Zhong Rong saw from their point of view the destructive effect of the metaphor on literary language and even the literary creation style, which is certainly an unavoidable aspect. In fact, for the authors of XuanYan poetry, the creation of XuanYan poetry is only a process of their body Xuan and Chang Xuan. They focus on the perception and experience of XuanZi in the process, Art skills and aesthetic value are not their concern. Strictly speaking, these works only rely on the powerful or favorable literary form of poetry to achieve the practical purpose of disseminating and discussing philosophical theories or political enlightenment. Most of the authors use nonverbal discourse in their writing practice. Most of the works, strictly speaking, can not fall into the category of "literature," and their literary value can not be discussed.

However, on the other hand, the creation of mysterious words can not simply be understood as a failure of literary discourse practice. This is not only because in the actual creation of the metaphysical poetry, in addition to the metaphysical discourse, the poets tend to supplement some literary discourse with rich artistic value. More importantly, this kind of integration of philosophical discourse into the literary creation discourse In fact, there are merit in practice. Here to highlight one of the most direct and most important aspect, that is, the profound discourse of poetry practice on the impact of philosophical poetry.

As mentioned above, the essence of discourse of philosophical poetry is that philosophical discourse enters literary creation, presenting as the blending of philosophical discourse and literary discourse. Broadly speaking, philosophical poetry does not originate in the hymn verse, such as the "two elegant" "three odes" in the "Book of Songs" there is a lot of talk about poetry. Ching-hsien Zhang Yi-yi pointed out: "All-encompassing, nonsense," three hundred "Ya Chung is also." He also believes that "poetry talk, Zhao Zhisong." Ye Xie "original poem" also said in fact, many of the philosophical discourses in The Book of Songs have become famous, such as "Xiaoya Xiaowan" Of the "warm temperature Christine, gathered in the wood. Villain, such as in the valley. Trembling, walking on thin ice." Another example is "Zhou Song • long hair" in the "days off, Just not gentle. "

To philosophize into poetry is not the first mysterious poem, but Yuanyan poem in the development of philosophical poetry is an essential part. On the one hand, it is natural for poetry to be involved in the discussion of the narrative in the lyrical narrative, whereas the metaphorical poet consciously and consciously applies the philosophical discourse to the literary creation. Metaphysical poetry has created a precedent, that is, the specific discourse of a particular philosophical concept begins to directly enter the practice of literary discourse. In this respect, there are the Buddhist poems of Tang Dynasty, the Buddhist poems of Wang Wei and the science poems of Song Dynasty. One of the Tang Dynasty's poems is the interpretation of Buddhism and Taoism, respectively, with the theme and scene as the theme of the poem, which has obvious lineage with the profound verse poetry, Wei and Jin Metaphysical poets branch, Yang Xi as its creative pilot.

On the other hand, Hyun-poem poetry makes extensive use of various imaginary languages in the interpretation of Yi-li, which has a far-reaching impact on the development of philosophical poetry. Regardless of narrative, lyricism or reasoning, poetry as a literary form, its literary expression is always due. Metaphysical poetry uses a large amount of imaginary language (including landscape imagery) in elucidation of justice. Although the original intention of the hymnist poem writing is beyond this, and is far from truly "emotional" blend, but its creation process is still an early test of the use of visual language. In fact, in later works by poets such as 
Wang Wei and Su Shi, we can see the clear traces of the way of trying to explain the philosophical discourse through images.

In a word, although the value of Xuan Yan Poems as a literary and artistic product itself is relatively limited, the creation of Xuan Yan Poems as an experimental discourse practice is undoubtedly far-reaching and complicated for the influence of ancient Chinese literature, especially poetry. There are many positive factors among them, and provide many enlightenments for the study of literary discourse in contemporary academic circles.

\section{References}

[1] Yongtong Tong: "Wei and Jin Metaphysics on draft", Shanghai: Shanghai Ancient Books Publishing House, 2001 edition.

[2] Feng Youlan: "History of Chinese Philosophy", Shanghai: East China Normal University Press, 2000 edition.

[3] Zhu Ziqing, Cai Qingfu and other editors, "Zhu Ziqing anthology", Shijiazhuang: Hebei Education Press, 1989 edition.

[4] Mu Kehong, Guo Dan editor: "Wei, Jin and Northern and Southern Dynasties literature review", Shanghai: Far East Press, 2012.

[5] Yu Guanying: "Han and Wei Dynasties Poetry Collection", Beijing: Commercial Press, 2010. 